\title{
NECTARIOS EXTRAFLORALES EN TURNERA, SERIES CANALIGERAE Y LEIOCARPAE
}

\author{
por ANA MARIA GONZALEZ 1
}

\begin{abstract}
Summary
This paper describes the anatomy of extrafloral nectaries of seventeen species of Turnera, belonging to Canaligerae and Leiocarpae series.

Foliar nectaries are born on the petiole apex or at the base of leaf blades; they are discoid, cupular with a rim surrounding a cup. Although size and morphology are variable among species, the structure of the nectaries is basically the same. They are composed of a secretory epidermis, which consists of 1-4 layers of columnar cells. Underlying this tissue, there are usually 2-8 layers of glandular parenchyma. The body of the nectary is formed by ground parenchyma; druses of calcium oxalate and tannin idioblasts are abundant in this area.

The vascular supply derives from the median petiole bundle. It is provided by 1 or 2 lateral bundles which branch repeatedly in the ground parenchyma of the nectary. In all the studied nectaries the vascular tissue ends as isolated strands of phloem among the secretory Jarenchyma cells. For the first time, tracheoids are described in nectaries; this elements were only known in the veinlets of Angiosperm's leaves.

Most of the species of series Canaligerae, have a "pore" in the secretory epidermis, which is in fact a protuberance determined by the glandular parenchyma; the surface is flat or crateriform. A thick cuticle covers the epidermis, only in the center of the "pore» it is thin enough to allow the nectar extrusion. In no species was observed cuticle rupturing. In the Leiocarpae nectaries the "pore" is less developed or absent.
\end{abstract}

\section{Introducción}

Los nectarios son estructuras secretoras de néctar de diversa morfología y anatomía; su posición en el cuerpo de la planta determinó una primera distinción en nectarios florales (NF) y extraflorales (NEF) realizada por Caspary (1848). Delpino (1875) los clasificó en nupciales y extranupciales de acuerdo a su relación con la polinización. Elias \& Gelband (1976) usaron los términos floral y extrafloral en el sentido dado por Delpino; los NF se encuentran en diversas partes de la flor y están relacionados con la polinización y los NEF pueden localizarse en los órganos vegetativos o

1 Becariá de Perfeccionamiento del COi JICET, Inst. de Boténica del ivordeste, UNNE, CC: 209. Corrientes. E-Mail: anamaria@unneca.edu.ar.

Este trabajo forma parte de la tesis doctoral a ser presentada en la Universidad de Córdoba. reproductivos, pero no se hallan asociados directamente con la polinización.

Se han propuesto varias clasificaciones de nectarios extraflorales las cuales son estrictamente topográficas (Fahn, 1979; Schmid, 1988). La clasificación más completa es la propuesta por Zimmermann (1932), quien basándose principalmente en la estructura y posición reconoció seis categorías de NEF: amorfos (Gestaltlosennektarien), planos (Flachnektarien), hundidos (Grubbeenektarien), en cavidades (Hohlnektarien), tricomas secretores (Schuppennektarien) y nectarios elevados (Hochnektarien). Elias (1983) adicionó una séptima categoría: nectarios embebidos (Eibettnnektarien) y los separó en vascularizados y no-vascularizados.

La literatura existente sobre los NEF es muy extensa y abarca diversos enfoques: aspectos morfológicos (Keeler \& Kaul, 1979; Fahn, 1952, 1953, 1979 a, 1988); estudios anatómicos (Frey- 
Wyssling, 1955; Arbo, 1972; Durkee et al. 1981; Durkee, 1982; Okoli \& Onofeghara, 1984; TothSoma \& Gulyás, 1991; Morellato \& Oliveira, 1994); mecanismo de la secreción (Fahn, 1979 b; Rachmilevitz \& Fahn, 1975); química del néctar y relaciones ecológicas (Bentley, 1977; Schemske, 1982; Mc Lain, 1983; O’Dowd \& Catchpole, 1983; Lanza, 1988; Mc Key, 1988; Koptur, 1992).

Los NEF de la familia Turneraceae fueron analizados por Berger (1919) quien describe glándulas ligeramente pedunculadas, de superficie secretora levemente convexa con una abertura excéntrica. Entre las especies estudiadas se encuentran Turnera ulmifolia L., $T$. hermannioides A.St.-Hil., A.Juss. \& Cambess., T. subulata Sm. y T. cuneiformis Poir.

Elias et al. (1975) describieron los NF y NEF de T. ulmifolia incluyendo el análisis del néctar secretado. Bahadur et al. (1985) estudiaron los NF de T. subulata y T. ulmifolia. También fue analizada la anatomía de los NF de $T$. Hassleriana Urb., T. Joelii Arbo y Piriqueta racemosa (Jacq.) Sweet (González, 1993).

En Passiflora L. se realizó un extenso trabajo sobre NF y NEF, analizando la anatomía antes y durante la secreción de néctar, con microscopio óptico y electrónico (Durkee et al. 1981; Durkee, 1982). En las Passifloráceas también se estudió la relación existente entre los NEF y las hormigas (Bentley, 1977; Mc Lain, 1983). Los nectarios extraflorales de Passiflora y Turnera son considerados homólogos por Elias (1983).

El presente trabajo es un estudio morfológico y anatómico de los nectarios extraflorales del género Turnera, abarcando doce especies de la serie Canaligerae, de las cuales ocho pertenecen al complejo T. ulmifolia, y cinco especies de la serie Leiocarpae (Arbo 1986, 1987, 1993).

\section{Material y Métodos}

Se analizó material vivo, cultivado en el invernáculo de la Fac. de Ciencias Agrarias, UNNE (\#), material fijado en FAA $\left(^{*}\right)$ y material de herbario ( ). Los ejemplares de herbario se rehidrataron previamente en agua jabonosa caliente y el material vivo fue fijado en FAA durante 48 horas.
Para el estudio anatómico se realizaron preparados permanentes, la deshidratación se llevó a cabo mediante una serie creciente de alcohol butílico terciario. El material fue incluido en Histoplast y se efectuaron cortes transversales seriados de pecíolo y hoja con micrótomo rotativo, en espesores de 8-10 $\mu \mathrm{m}$.

Los cortes se colorearon con safranina - «fast green» (Johansen, 1940) o safranina - azul de Astra (técnica usada en el Instituto de Biociencias, Universidad de Sâo Pablo, Brasil; extraída de Gabe, 1968). En los nectarios de hojas jóvenes se usó la técnica de Foster (1934), tratándose los cortes con $\mathrm{ClFe}$ y ácido tánico antes de la coloración habitual.

Para el análisis de la vascularización se realizaron cortes seriados. También se diafanizaron hojas con la técnica de Dizeo de Strittmatter (1973) que se colorearon con safranina. Para determinar la presencia de estomas se efectuaron extendidos de epidermis, tratando el material con $\mathrm{NaOH} 10 \%$ y coloreándolo con Lugol.

Los dibujos se realizaron con el auxilio de la cámara clara de un microscopio Wild M 20; en los esquemas el xilema se representa con rayado vertical (Metcalfe y Chalk, 1979).

Las observaciones con MEB se realizaron en el Centro Regional de Investigaciones Básicas y Aplicadas de Bahía Blanca. Se usó material fijado en FAA, se deshidrató en una serie ascendente de acetona y fue secado a punto crítico con $\mathrm{CO}_{2}$. La metalización se llevó a cabo con un delgado baño de oro en una metalizadora Pelco 3 Sputter Coater 91000. Las observaciones se realizaron en un microscopio electrónico de barrido JEOL 35 CF operado a $5 \mathrm{kV}$, usándose film VP 120 Kodak para las microfotografías.

Se detalla a continuación el material estudiado; los ejemplares testigo están depositados en el Herbario del Instituto de Botánica del Nordeste (CTES).

\section{Serie Canaligerae:}

\# Turnera hermannioides Cambess. Arboet al. 5680, cultivada en Corrientes, procedente de Brasil, Bahía.

\# Turnera Joelii Arbo. Barret \& Shore 1373, cultivada en Corrientes, procedente de Brasil, Bahía, río Juremal. 
* Turnera simulans Arbo. Arbo et al. 5710, Brasil, Bahía, Municipio Barra da Estiva, $8 \mathrm{Km}$ S Barra da Estiva, camino a Ituaçu: Morro do Ouro y Morro da Torre, elev. 1190-1290 m.

* Tumera stenophylla Urb. Arbo et al. 5319, Brasil, Bahía, Municipro Gentio do Ouro, alrededores de Santo Inácio y hasta $9 \mathrm{Km}$ al $\mathrm{N}$ del camino a XiqueXique, Serra de Açuruá, elev. 500-550 m.

\section{Complejo T.ulmifolia:}

\# Turnera Aurelii Arbo. Schinini 23860, cultivada en Corrientes, procedente de Paraguay, río Salado, camino de limpio a Emboscada.

\# Turnera cuneiformis Poirel. Arbo et al 4985, cultivada en Corrientes, procedente de Brasil, Minas Gerais, Conceiçao do Mato Dentro.

\# Turnera Krapovickasii Arbo. Schinini 19514, cul-. tivada en Corrientes, procedente de Argentina, Salta, Dpto. Anta, Гl Quebrachal, Ruta 16. Krapovickas et al. 38858, cultivada en Corrientes, procedente de Bolivia, Dpto. Tarija, $4 \mathrm{Km} S$ de Entre Ríos.

\# Tumera onentalis (Urb.) Arbo. Schinini et al. 24717, cultzvada en Corrientes, procedente de Argentina, Misiones, Dpto. San Ignacio, Peñón Reina Victoria, río Paraná.

\# Turnera scabra Millsp. Breedlove 47230, cultivada en Corrientes, procedente de México, Chiapas, Catazaja.

\#Tumera subulata Sm. Arbo 2410, cultivada en Corrientes, procedente de Brasil, Maranhao, Sao Luis.

\# Turnera ulmifola L. Arbo 2698, cultivada en Corrientes, semillas procedentes de USA, Florida, Miams.

\# Turnera velutina Presl. Koch \& Fryxell 78341 bis, cultivada en Corrientes, procedente de Mćxico, Oaxaca, Santo Domingo.

\section{Serie Leiocarpae:}

\# Tumera Hasslenana Urb. Vanni et al. 395, cultivada en Corrientes, procedente de Paraguay, Dpto. Concepción, $12 \mathrm{Km}$ NE de Loreto, camino a Paso Barreto, Hugua Pol, 205 m.s.m. * Arbo et al. 6082, Paraguay, Paraguarí, $2 \mathrm{Km}$ L de ruta PiribebuyParaguarí, sobre el desvío a ltá-Morotí y Valenzuela, elev. ca. $200 \mathrm{~m}$.

"Tumera nervosa Lrirb. Arbo 2076, Argentina, Corrientes, Dpto. Ituzanngó, Rincón Ombú Chico.

* Turnera oblongifolia Cambess. Mello Silva et al. 603, Brasil, Minas Gerais, Buenopolis, estrada para Curimataí.

*'Tumnera opifera Mart. Mello Silva et al. 636, Brasil, Minas Gerais, Itacambira, estrada Itacambira,
Pau-d'Oleo, $16 \mathrm{Km}$ de Itacambira. Mello Silva et al. 641, Brasil, Minas Gerais, Botumirin, Serra da Canastra, extremidade Vorte da Serra proximo a estrada para Itacambira, base da Serra Tinoco, 970 ms.n.m.

\# Turnera pumilea L. Krapovickas et al. 38624 bis, cultivada en Corrientes, procedente de Brasil, Praui, $3 \mathrm{Km} \mathrm{W}$ de Oeiras.

\section{Observaciones}

Las hojas de Turnera tienen nectarios discoideos, circulares o elípticos (Fig. 1 A, C); su diámetro es variable: $0,3 \mathrm{~mm}$ para los más pequeños y hasta $1,8-2 \mathrm{~mm}$ para los mayores. La mayoría son sésiles, pero T. ulmifolia tiene los NEF sobre pequeñas expansiones de la lámina y en T. Hassleriana y $T$. pumilea los NEF son brevemente estipitados. Se hallan ubicados de a pares a ambos lados del pecíolo, en la unión con la lámina foliar (Fig. I A, D; 2 G) o desplazados sobre el margen de la lámina (Fig. $3 \mathrm{~F} ; 4 \mathrm{~F} ; 5 \mathrm{~A}$ ); pueden orientarse lateralmente (Fig. 2 G; 3 F) o hacia el envés de la hoja (Fig. 2 A; 4 D, F; 5 A, D, F). En ciertas especies como T. hermannioides y $T$. Krapovickasii, algunas hojas tienen tres o cuatro nectarios.

Las flores de estas series de Turnera son epifilas. De acuerdo al grado de adnación entre el pedúnculo floral y el pecíolo los NEF pueden quedar junto al receptáculo floral (Fig. I E; 2 D) o más o menos alejados del mismo.

Los NEF poseen reborde elevado, en general pilosiúsculo y tienen una zona central generalmente deprimida (Fig. $1 \mathrm{~A}$ ), menos frecuentemente elevada y convexa (Fig. 1 C, D).

Los nectarios extraflorales de las especies de Tumera analizadas son intensamente visitados por hormigas, especialmente aquellos ubicados en las hojas portadoras de flores, en la porción superior de la planta; en estos nectarios se observó la mayor producción de néctar. La secreción de néctar comienza muy temprano en el desarrollo, se inicia cuando la hoja no ha completado aún su crecimiento.

Los NEF son frecuentemente cubiertos por Hyphomycetes, los géneros más frecuentes de estos hongos epífilos son Acladium, Spegazzinia y Alternaria. El crecimiento del hongo se inicia siempre en la zona del "poro». 

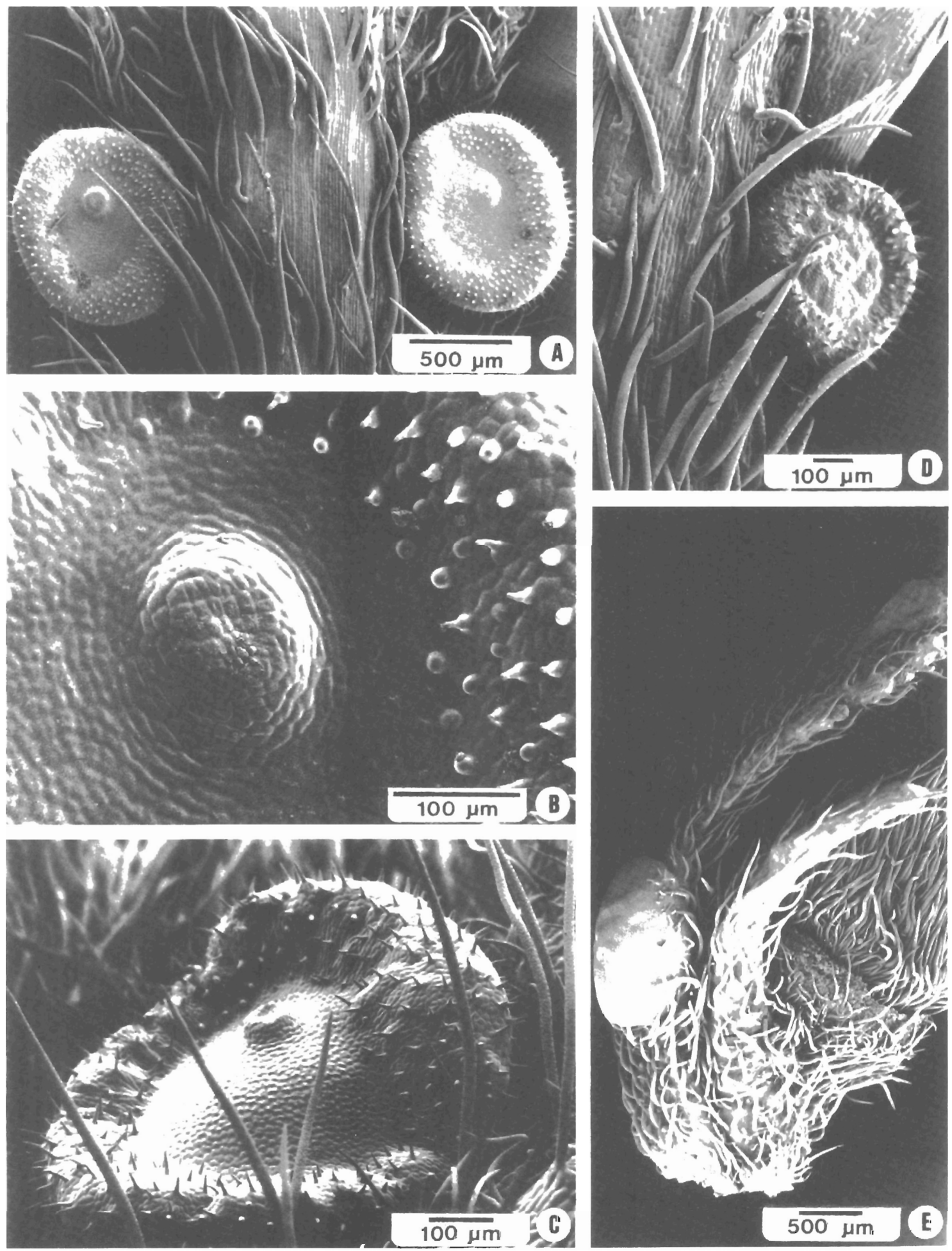

Fig. 1. Nectarios extrafloraies observados con MEB. A-B: T cuneiformis; A. par de NEF en la unión del pecíolo y lámina foliar. B: deta.lle del «poro» en la depresión central del NEF. C: T. Krapovickasii, detalle del NEF. D: T. nervosa, NEF en la unión del peciolo y lámina foliar. E: $T$ opifera, porción de un fruto epifilo con su correspondiente profilo y el NEF en la hoja axilar. 


\section{Serie Canaligerae}

Observando el NEF con microscopio estereoscópico, se puede apreciar en la depresión central un «poro» ligeramente elevado por el cual se produce la salida del néctar; visto al MEB este «poro» es una prominencia generalmente ubicada en el cuadrante superior externo o en la línea media del NEF (Fig. 1 A, B, C). En transcorte, los NEF son cupuliformes (Fig. 2 $\mathrm{G}, \mathrm{H}, \mathrm{p}$ ).

Seguidamente se detallan los caracteres anatómicos comunes de los NEF.

Epidermis: En los rebordes elevados del nectario, la epidermis posee células cuadrangulares con la pared externa convexa, el núcleo es conspicuo y está desplazado hacia la pared tangencial interna por una gran vacuola.

Casi todos los NEF poseen pelos simples, unicelulares y pequeños de $25-40 \mu \mathrm{m}$ de long., ubicados en los rebordes (Fig. 1 B, C); tienen pared lignificada de grosor variable, y su núcleo también tiene posición interna (Fig. 4 C). Solamente $T$. hermannioides tiene pelos estrellados de 2-5 brazos (Fig. 3 E).

En la depresión central del NEF se halla una epidermis en empalizada (Fig. 2 C, I; 3 C, G; 4 B, E, e), sus células de paredes delgadas son columnares, alargadas radialmente y se disponen apretadamente. Poseen características glandulares: citoplasma muy denso, finamente granuloso, intensamente coloreado, con numerosas vacuolas; el núcleo es conspicuo y de posición central, posee cariolinfa granulosa y un solo nucleolo.

La epidermis secretora varía entre las especies, desde unistrata en T. Krapovickasii (Fig. 4 B, e) a 4-estratificada en T. simulans (Fig. 2 B, C, e), siendo generalmente biestratificada. Las divisiones celulares periclinales pueden ocurrir todas al mismo nivel o a distintas alturas e inclusive pueden presentarse divisiones oblicuas, pero siempre quedan formadas columnas de células.

En corte transversal el «poro» es una elevación de la epidermis secretora causada por un abultamiento del parénquima subepidérmico. De acuerdo a la disposición y altura de las células epidérmicas que cubren esta protuberancia, se distinguen dos formas de «poro»: a. Crateriforme: las céluias centraies son notablemente más bajas que las laterales (Fig. 2 B, $\mathrm{H} ; 4$ B, p).

b. Mesetiforme: la zona central del «poro» es llana (Fig. 3 B, C, 4 E, p).

Las células epidérmicas que componen el centro del "poro" pueden presentar la pared externa lisa (Fig. $3 \mathrm{G}$ ), convexa (Fig. 2 r; 4 B) o apezonadas (Fig. $2 \mathrm{C} ; 3 \mathrm{C}$ ).

La cutícuia que cubre la epidermis se engruesa gradualmente desde la cara adaxial de la hoja hacia los rebordes de la cúpula nectarífera, donde llega a tener unos $5 \mu \mathrm{m}$ de espesor, se incrusta entre las células epidérmicas y recubre también los pelos. En los límites externos de la epidermis secretora con los rebordes del nectario, la cutícula posee cuñas que penetran profundamente.

Sobre la epidermis secretora la cutícula aumenta el espesor llegando a tener hasta 20-25 $\mu \mathrm{m}$ de espesor (Fig. $2 \mathrm{H}$ ); gradualmente se adelgaza sobre el «poro» y en el centro del mismo cubre las células epidérmicas o se incrusta entre ellas cuando son apezonadas o de pared externa convexa (Fig. 2 C, I; 3 C; 4 B). T. Aurelii también posee cuñas de cutícula en la base del «poro» y en $T$. stenophylla están en el centro mismo del «poro» (Fig. $3 \mathrm{G}$ ).

La cutícula generalmente se separa de la epidermis, quedando adherida por las cuñas; se forma así una cavidad donde se acumula el néctar. En ninguna de las especies estudiadas se encontraron estomas en la epidermis secretora, ni en la epidermis de los rebordes de la cúpula nectarífera.

Parénquima glandular: se halla inmediatamente debajo de la epidermis secretora y está constituido por 4-8 capas de células; su espesor aumenta debajo del "poro" del nectario (Fig. 2 $C, r$ ). Son células isodiamétricas, con paredes delgadas que se ubican sin dejar espacios intercelulares (Fig. 2 C, I; 3 B, G, r). Tienen características glandulares idénticas a las células epidérmicas; en algunos casos, en el citoplasma se observan filamentos muy delgados y retorcidos.

El resto del cuerpo del nectario se halla constituido por tejido parenquimático. El límite entre el parénquima glandular y el parénquima fundamental es gradual, ocurriendo un aumen- 


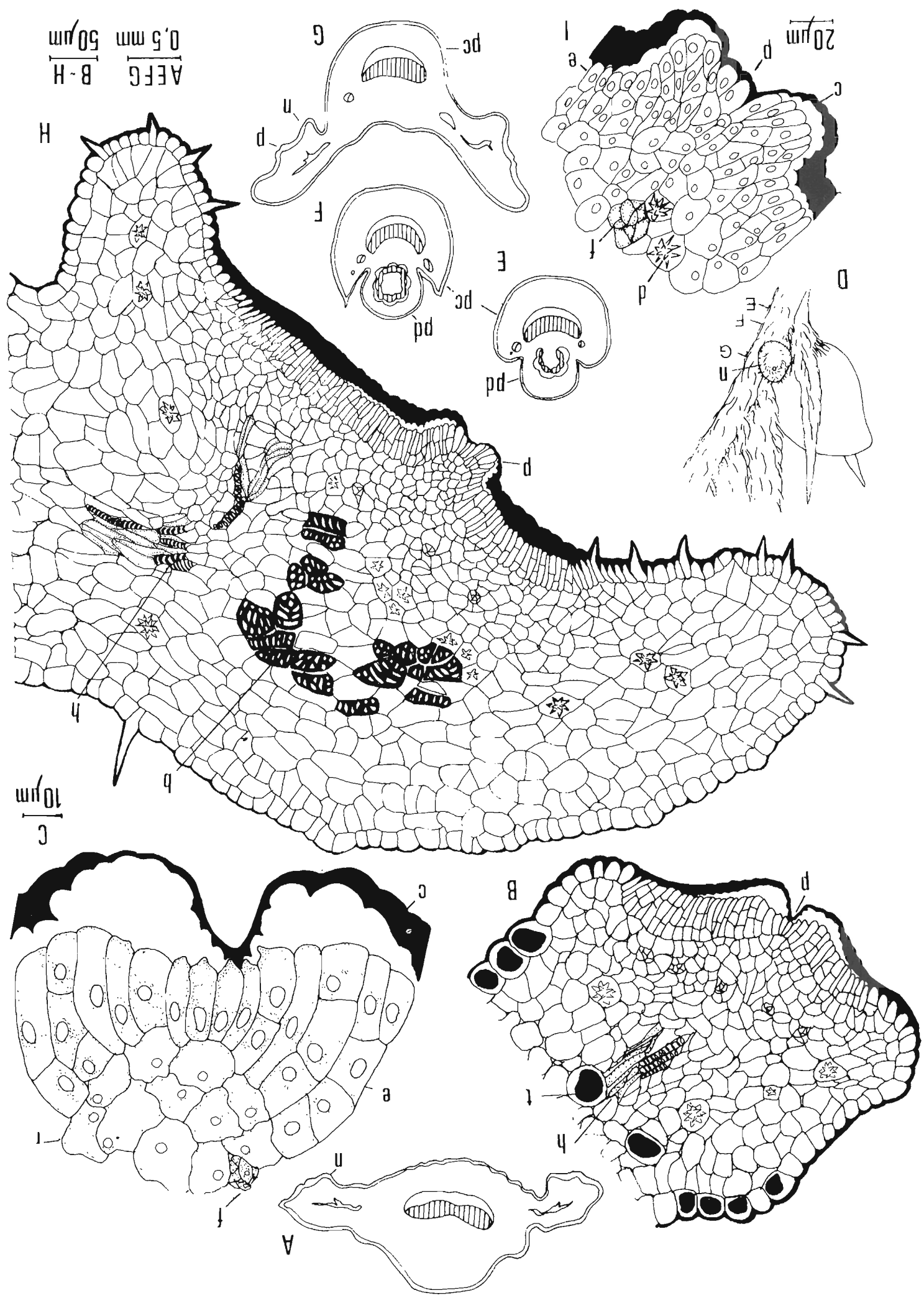


to del volumen celular y pérdida de las características secretoras (Fig. $2 \mathrm{H} ; 3 \mathrm{~B} ; 4$ B). Abundan las drusas, especialmente en el parénquima secretor o en los rebordes (Fig. 2 I, d; 3 B, C, d); nunca se las encuentra en la epidermis. En algunas especies hay células taníferas (Fig. 2 B, t).

Sistema Vascular: las trazas que inervan los NEF se desprenden de los extremos del haz peciolar, el cual forma un arco amplio (Fig. $2 \mathrm{E}$, $\mathrm{F}, \mathrm{pc}$ ). Al entrar al nectario se dividen en varias ramas que llegan hasta la base del parénquima glandular (Fig. 2 G, H, h). Los elementos vasculares son principalmente vasos anillados; las células terminales del floema penetran hasta el parénquima glandular, llegando hasta un par de capas por debajo de la epidermis secretora (Fig. 2 C, I; 3 G, f; 4 B).

Entre las ramificaciones del haz vascular, en el cuerpo del NEF de algunas especies se observan traqueoides (Foster, 1956), células esclerificadas grandes, isodiamétricas o ligeramente irregulares, con paredes escalariformes, reticuladas o punteadas. Estas células imperforadas son los elementos terminales del xilema (Fig. $2 \mathrm{H}, 3 \mathrm{D}, \mathrm{b}$ ). Pueden estar aisladas, como en T. hermannioides y $T$. ulmifolia, en grupos de dos a cuatro, como en $T$. orientalis y $T$. cuneiformis, o ser conspicuas y abundantes como en $T$. Aurelii en la que se cuentan hasta 20 en el centro del nectario, donde se ramifica el haz vascular.

A continuación se dan las características particulares encontradas en las distintas especies de la serie Canaligerae.

T. hermannioides: las hojas tienen nectarios en la unión de pecíolo y lámina, orientados lateralmente y hacia la cara abaxial de la hoja (Fig. $3 \mathrm{~A}$ ). Los rebordes poseen pelos de dos o tres brazos, mucho más pequeños que los que se encuentran en el pecíolo y lámina foliar (Fig. $3 \mathrm{E})$. La epidermis glandular tiene 2-3 capas de células, las divisiones ocurrieron a distintas alturas, observándose también divisiones oblicuas (Fig. 3 B, C, e). El "poro» es mesetiforme, las células centrales tienen la pared externa en forma de pezón. La cutícula externamente es lisa (Fig. $3 \mathrm{C}, \mathrm{e}, \mathrm{c}$ ), se halla incrustada entre las células centrales y separada del resto de la epidermis. El parénquima glandular tiene gran cantidad de drusas (Fig. 3 B, C, d).

Los traqueoides son escasos, aislados, con paredes reticuladas y punteadas (Fig. $3 \mathrm{D}, \mathrm{b}$ ). No posee células taníferas.

T. Joelii: los NEF están en la base de la lámina foliar, sobre el margen. Poseen pelos simples en los rebordes de la cúpula nectarífera. La epidermis secretora es de uni- a biestratificada, las divisiones celulares a diferentes alturas. El «poro» es crateriforme con las células centrales apezonadas. Hay drusas distribuidas por todo el NEF, pero son escasas en el parénquima secretor; no se observan células taníferas ni traqueoides.

T. stenophylla: los NEF están en la base de la lámina, orientados lateralmente; la superficie secretora es casi plana, los rebordes son inconspicuos (Fig. 3 F). No poseen pelos. El pecíolo está repleto de idioblastos con tanino, los que desaparecen abruptamente en los NEF. Las drusas son abundantes y no hay traqueoides. La epidermis secretora es de bi- a tristrata, despareja (Fig. 3 G, e); el "poro» es poco notable a inexistente, es una zona donde la epidermis se adelgaza ligeramente y la cutícula es delgada, pudiendo presentar cuñas que penetran muy profundamente en la epidermis secretora.

$T$. simulans: los NEF son muy pequeños, están en la base de la lámina sobre el margen, orientados hacia el envés de la hoja (Fig. $2 \mathrm{~A}$, n). Los pelos simples son ocasionales. La epidermis secretora varía de una sola capa en el centro del «poro», con células apezonadas, a 34 capas bastante parejas (Fig. 2 B, C, e). El «poro» es crateriforme y muy grande en relación al tamaño total del nectario (Fig. 2 B, p). Las células taníferas se distribuyen igual que en T.stenophylla. No se han observado traqueoides.

Fig. 2. A-C: Turnera simulans; A: corte transversal del peciolo y NEF; B: corte transversal del nectario; C: detalle del poro. D-I: T. Aurelii; D: vista proximal de una hoja con un fruto epifilo y un NEF; E-G: transcortes a distintos niveles marcados en la fig. D mostrando la vascularización de los NEF; H: corte transversal del nectario; I: detalle del poro. Abreviaturas: b: traqueoides, c: cutícula, d: drusas, e: epidermis secretora, f: ramas floemáticas, h: haz vascular del NEF, n: nectario, p: poro, pc: peciolo, pd: pedúnculo floral, r: parénquima glandular, t: células taníferas. 


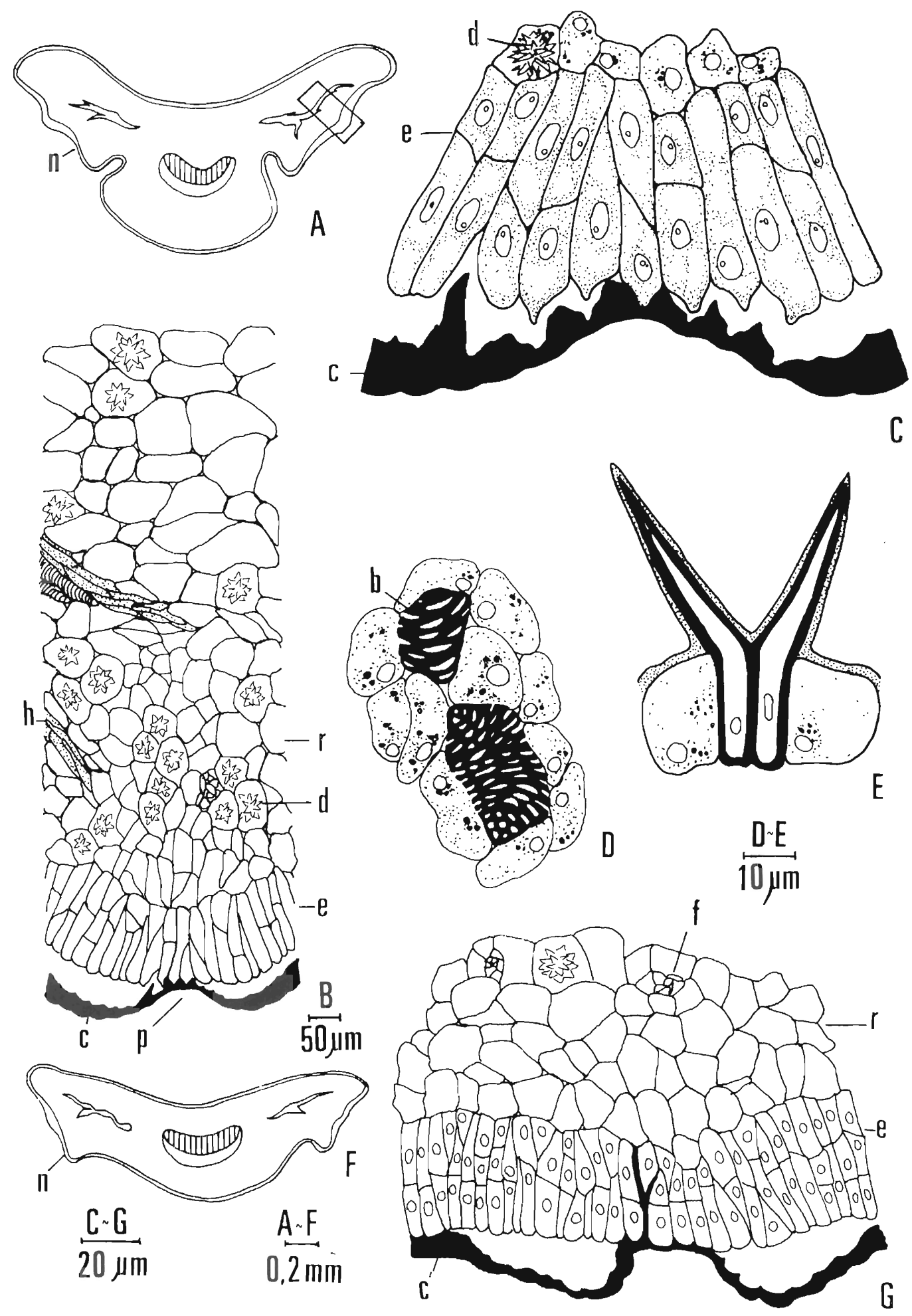

Fig. 3. A-E: Turnera hermanitioides; A: corte transversal del pecíolo y NEF; B: detalle del sector marcado en A; C: detalle de las células del poro; D: traqueoides; E: pelo estrellado. F-G: T. stenophylla; F: corte transversal de la base de la lámina a la altura de los NEF; G: detalle de la epidermis secretora. Abreviaturas: b: traqueoides, c: cutícula, d: drusas, e: epidermis secretora, f: ramas floemáticas, h: haz vascular del NEF, n: nectario, p: poro, r: parénquima glandular. 


\section{Complejo T. ulmifolia}

T. Aurelii: los NEF están ubicados en la unión del pecíolo y lámina o en la base de la lámina foliar, se orientan lateralmente y están junto al receptáculo floral (Fig. 2 D, G, n). Poseen abundantes pelos simples en el reborde (Fig. 2 H). La epidermis glandular es de uni- a biestratificada, las divisiones ocurrieron a diferentes alturas (Fig. $2 \mathrm{H}, \mathrm{I}, \mathrm{e}$ ); el «poro» es típicamente crateriforme, las células centrales del mismo tienen la pared externa convexa (Fig. 2 I, p, e). Los traqueoides (Fig. $2 \mathrm{H}, \mathrm{b}$ ) poseen paredes muy lignificadas, de reticuladas a punteadas; en este caso las aberturas externas e internas de las puntuaciones están en cruz. Se observan drusas distribuidas en el parénquima (Fig. 2 I, d). No hay células taníferas en el NEF.

T. ulmifolia: los NEF están en la base de la lámina, sobre pequeñas expansiones de la misma. Los rebordes poseen pelos simples de pared gruesa. La epidermis secretora es uni- a triestratificada, el "poro» es mesetiforme con la pared externa de las células centrales completamente plana. Posee traqueoides de pared escalariforme. Hay numerosas drusas pero no existen células taníferas.

Los NEF de las restantes especies analizadas en este complejo presentan la misma organización descripta; poseen células con tanino distribuidas por el parénquima y acompañando al haz vascular. Las variables son la forma del «poro» y los traqueoides.

T. orientalis: el «poro» es mesetiforme, con células centrales notablemente apezonadas. Posee escasos traqueoides.

T. cuneiformis: los NEF están de a pares a ambos lados del pecíolo, orientados hacia el envés de la hoja (Fig. $1 \mathrm{~A}$ ); el «poro» es una elevación crateriforme ubicada en la mitad superior de la depresión central (Fig. 1 B), las células centrales del «poro» son apezonadas. Posee traqueoides en grupos de 2 - 4 elementos, generalmente escalariformes.

T. scabra: el "poro» es mesetiforme, la pared externa de las células centrales es convexa. No se observan traqueoides.

T. subulata: la epidermis secretora es bistrata con las divisiones al mismo nivei. El "poro» es mesetiforme, las células centrales tie- nen la pared externa convexa. No hay traqueoides.

T. Krapovickasii: son NEF grandes en relación al tamaño del pecíolo (Fig. 4 A, n); hay 2, 3 ó 4 por hoja. Son cupuliformes, pero la superficie secretora es marcadamente convexa (Fig. 1 C). La epidermis secretora es unistrata, el «poro» es crateriforme (Fig. 4 B, e, p; 1 C); las células centrales tienen la pared externa convexa. No se presentan traqueoides.

T. velutina: los NEF son pequeños (Fig. 4D), la epidermis secretora uni- a biestratificada y muy pareja (Fig. 4 E, e). El «poro», notablemente grande en relación al tamaño del NEF, es mesetiforme y sus células centrales tienen paredes externas lisas (Fig. 4 E, p). La cutícula no se separa de la epidermis secretora. No se observan traqueoides.

\section{Serie Leiocarpae}

La anatomía de estos nectarios es básicamente la misma descripta para los NEF de la serie Canaligerae. La principal diferencia radica en el menor desarrollo o ausencia del «poro». Una característica llamativa de casi todas las especies analizadas es la presencia de células taníferas; éstas forman un estrato continuo de 1-3 capas de células debajo de la epidermis secretora y se continúan por la epidermis de los rebordes (Fig. 4 G, 5 B, C, E, G, t); también son muy abundantes en todo el parénquima del NEF.

Se detallan a continuación las características principales de cada especie.

T. Hassleriana: los NEF de esta especie son pequeños, están en el envés de la lámina foliar, en su porción basal (Fig. $4 \mathrm{~F}$ ); son cupuliformes (Fig. $4 \mathrm{G}$ ) y vistos con el microscopio estereoscópico se observa la presencia del «poro» ubicado en la línea media de la porción superior del NEF. Los rebordes poseen numerosos pelos sımples, con pared lignificada muy gruesa. La epıdermis secretora es bistrata, bastante pareja; en la zona del «poro» esta epidermis es unistrata y se halla elevada por un abultamiento del parénquima glandular subyacente; todas las células del «poro» tienen la pared externa plana (Fig $4 \mathrm{H}, \mathrm{e}$ ). Al «poro» se lo podría clasificar como mesetiforme ya que to- 

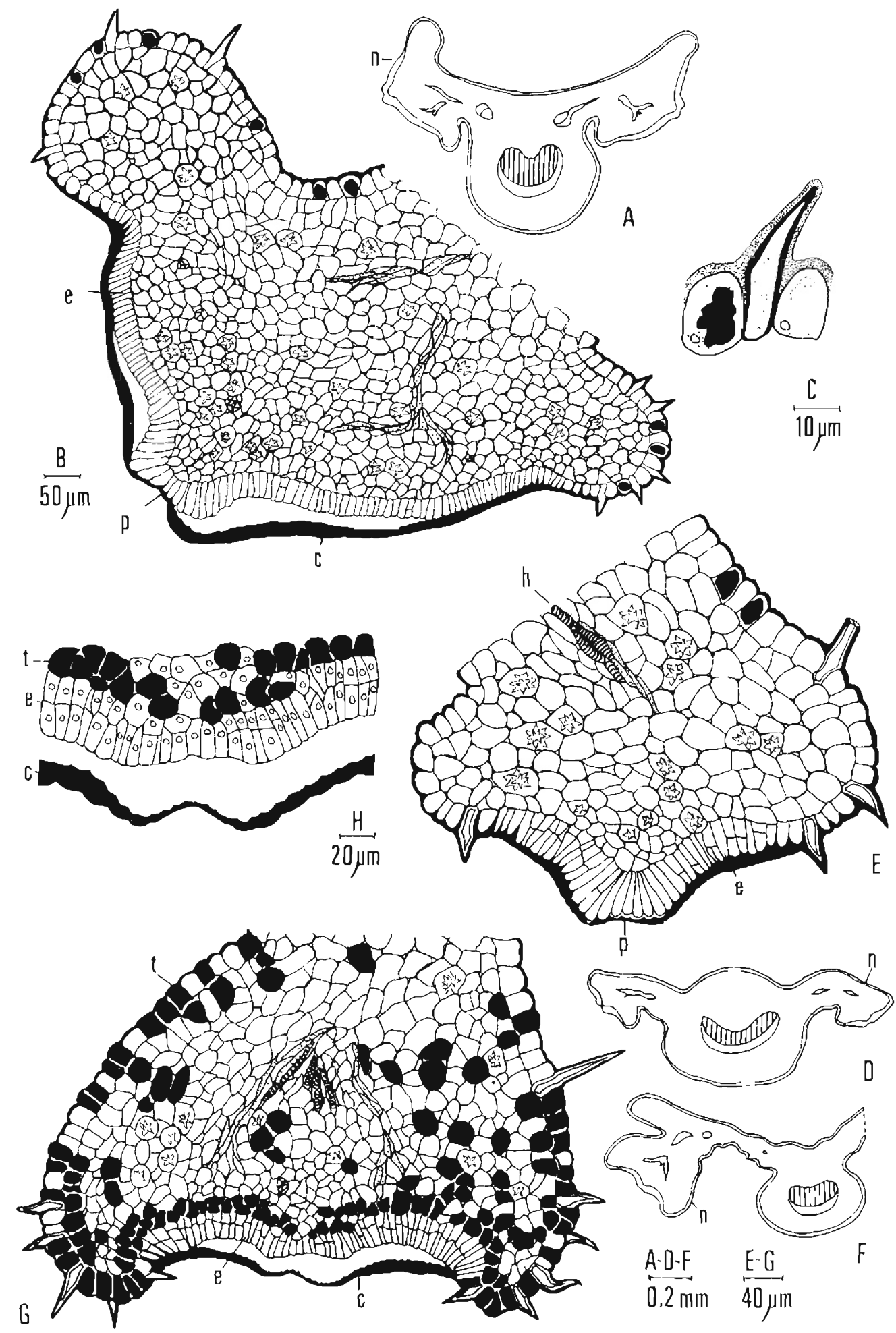

$\mathrm{E}$
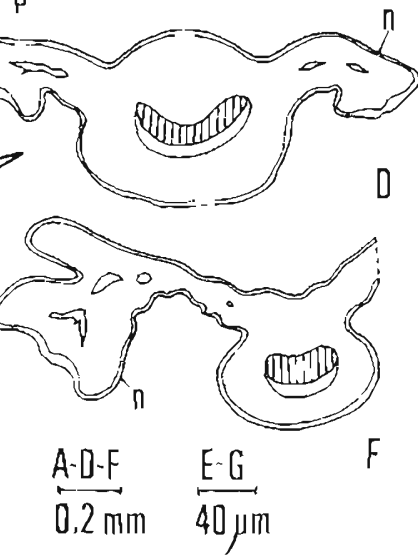

Fig 4. A.C. Turnera Kropovickasii; A. corte transversal del peciolo y NEF; B: corte transversal del NEF; C. pelo sımple. DE: T. velutina; $\mathrm{D}$ : transcorte de la base de la lámina foliar a nivel de los NEF; E: corte transversal del nectario. I'- $\mathrm{H}: T$ Hassleriana; Fi transcorte de la base de la lámina foliar a la altura de los NEF; G: corte transversal del NEF; H: detalle del poro. Abreviaturas: c: cutícula, e: epidermis secretora, h: haz vascular del NEF, n: nectario, p: poro, t: células taníferas. 
das las células que lo constituyen componen una superficie plana; la cutícula se adelgaza gradualmente sobre el "poro» y posee cuñas entre las células centrales, externamente es ondulada y se separa de la epidermis (Fig. $4 \mathrm{H}, \mathrm{c}$ ). No hay traqueoides.

T. pumilea: los NEF están en el envés de la hoja, son obcónicos por ser brevemente estipitados (Fig. $5 \mathrm{~A}$ ). No poseen rebordes, pero lateralmente tienen pelos robustos de paredes gruesas (Fig. 5 B). La epidermis secretora es plana, de uni- a biestratificada, cubriendo inclusive los rebordes del NEF. No existe "poro", la cutícula es de grosor uniforme y está fuertemente adherida a la epiderm is secretora (Fig. 5 $B, C, e, c)$. Presenta sólo el estrato tanífero continuo subepidérmico, en el cuerpo del nectario las células taníferas acompañan al haz vascular; en el resto del parénquima hay numerosas drusas. Las últimas ramas floemáticas llegan hasta el estrato tanífero (Fig. 5 C, t, f). No hay traqueoides.

T. oblongifolia: posee un par de NEF en la unión del pecíolo y la lámina, en los márgenes de la misma (Fig. 5 D). Son cupuliformes, los rebordes poco notables y ocasionalmente con pclos simples (Fig, 5 E). La epidermis secretora puede presentar una zona más delgada donde se incrusta la cutícula, pero no llega a formar un "poro", la cutícula es de grosor uniforme y puede separarse de la epidermis. Tiene escasos traqueoides terminales.

T. opifera: los NEF se encuentran preferentemente en las hojas superiores y fértiles de la planta, las que tienen menor desarrollo. Tienen forma subesférica, no presentan rebordes; se ubican en los márgenes de la base de la lámina, hacia el envés de la hoja (Fig. $1 \mathrm{E} ; 5 \mathrm{~F}, \mathrm{n}$ ). La epidermis secretora es de uni- a bistrata (Fig. 5 $\mathrm{G}, \mathrm{H}, \mathrm{e})$, ocasionalmente puede presentar disminuciones de su espesor, pero no son constantes en número ni en posición, por lo que no se consideran como "poros"; la cutícula es de grosor uniforme y usualmente está separada de la epidermis secretora, puede presentar cuñas (Fig. $5 \mathrm{G}, \mathrm{H}, \mathrm{c}$ ). Poseen un estrato tanífero subepidérmico continuo y numerosas drusas en el parénquima (Fig. $5 \mathrm{H}, \mathrm{t}, \mathrm{d}$ ).

$T$. nervosa: posee NEF cupuliformes semejantes a los encontrados en el complejo $T$. ulmifolia pero sin "poro» (Fig. 1 D). No hay estrato tanífero. Posee traqueoides de paredes escalariformes.

\section{Discusión y Conclusiones}

Los nectarios cupuliformes son los más frecuentes en la serie Canaligerae; las especies analizadas de la serie Leiocarpae presentan rebordes poco conspicuos, son ligeramente estipitados en $T$. pumilea y subesféricos en $T$. opifera. Por ser cupuliformes o discoideos, pero distintivamente elevados de la superficie, los NEF de Turnera se ubican en la categoría de nectarios elevados (Hochnektarien) de la clasificación de Zimmermann (1932)

La anatomía en todos los casos responde a un mismo esquema esencial. La epidermis secretora posee células alargadas, las que al sufrir una a tres divisiones transversales u oblicuas, forman columnas que Elias et al. (1975) denominaron cuerpos secretores. En el parénquima son numerosas las céluras con drusas.

Las especies de la serie Canaligerae y algunas del complejo T. ulmifolia carecen de células taníferas, a pesar de ser abundantes en el pecíolo, como por ejemplo en $T$. stenophylla y $T$. simulans. Sin embargo en las especies de la serie Leiocarpae forman un estrato subepidérmico continuo. La presencia de compuestos tánicos ya fue citada como una característica del parénquima glandular de los NEF (Elias, 1983), también fueron encontrados en ios NEF de Passiflora (Durkee, 1982).

Todos los NEF observados son vascularizados por una o dos trazas laterales derivadas del haz peciolar. El hacecillo que entra al NEF se ramifica varias veces, en todas las especies las últimas ramas son estrictamente floemáticas. Lo mismo ocurre en ias especies de Passiflora anaiizadas por Durkee (1982) y en Passiflora caerulea L. (observación personal). Sin embargo Elias et al. (1975) encontraron en $T$. ulmifolia que las últimas vénulas del NEF están formadas por xilema y floema.

Se encontraron elementos esclerificados en cinco especies de la serie Canaligerae, justamente las que presentan NEF de mayor tamaño: $T$. Aurelii, $T$. hermannioides, $T$. orientalis, $T$. cuneiformis y T. ulmifolia; Elias et al. (1975) no los observaron en csta última especie. En la 


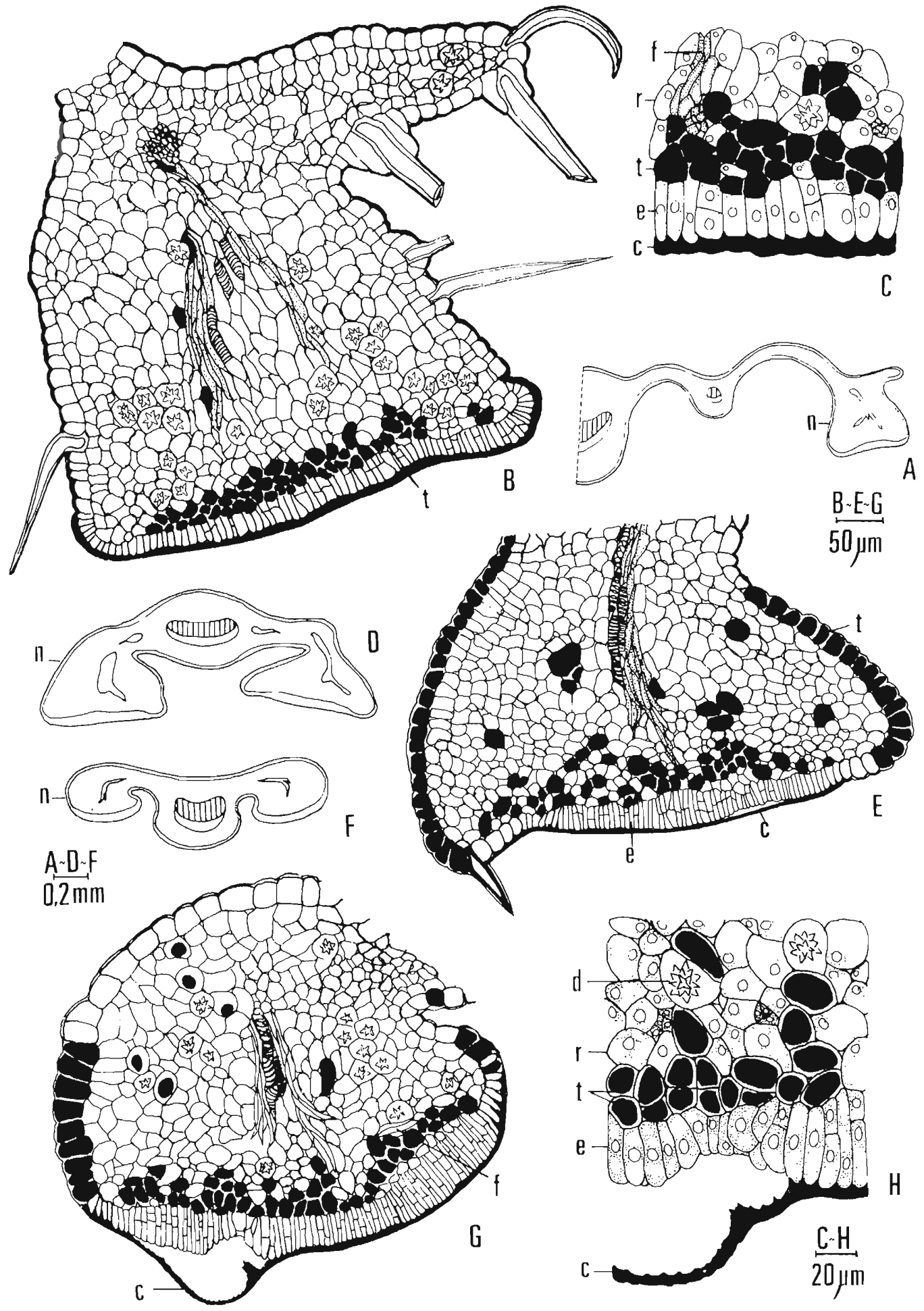

Fig. 5. A-C: Turnera pumilea; A. transcorte de la lámina foliar a la altura de los NEF; B: corte transversal del NEF; C: detalle de la epidermis secretora. D-E: T. oblongifolia; D: transcorte de la base de la lámina y NEF; E: corte transversal del nectario. F-H: T opifera; F: transcorte del pecíolo y NEF; G: corte transversal del nectario; H; detalle de la epidermis secretora. Abreviaturas: c: cutícula, d: drusas, e: epidermis secretora, f: terminales floemáticas, h: haz vascular del NEF, n: nectario, p: poro, r: parénquima glandular, t; células taniferas. 
serie Leiocarpae están presentes en T. oblongifolia y en $T$. nervosa, con menor grado de lignificación de las paredes. Estos idioblastos están ampliamente distribuidos en el mesófilo de las hojas de dicotiledóneas y generalmente están relacionados con las vénulas (Tucker, 1964; Metcalfe \& Chalk, 1979; Rao, 1991). Fueron denominados traqueoides (tracheoid idioblasts o tracheoidal elements) por Foster (1956) y Tucker (1964), por poseer los engrosamientos de sus paredes semejantes a los elementos traqueales y diferir en la forma, tamaño y posición.

Rao realizó extensos estudios en diversas familias (Rao \& Das, 1979; Rao \& Chakraborti, 1982; Rao, 1991); propone una vasta clasificación de los traqueoides, denominando braquitraqueoides a aquellos que poseen engrosamientos helicados (Rao \& Das, 1979) y esclerotraqueoides a los que tienen paredes gruesas y punteadas (Rao \& Chakraborti, 1982). Como los elementos encontrados en Turnera poseen características intermedias, en las descripciones se los denomina simplemente "traqueoides». Estos elementos son descriptos por primera vez para nectarios extraflorales, habría que comprobar su presencia en el mesófilo de Turnera, género no estudiado por Rao (1991).

Berger (1919) observó que en los NEF de Turnera el néctar se acumula bajo la cutícula que permanece intacta y expresa que la salida del mismo se produce a través de una abertura excéntrica u "ostíolo». Sin embargo el citado autor no describió la anatomía del «ostíolo».

La contribución original de este trabajo consiste en describir esta estructura, a la cual se denomina "poro». Anatómicamente no existe ninguna abertura, dicho "poro» es una protuberancia del parénquima glandular que eleva la epidermis secretora en una zona limitada de la depresión central de la cúpula del nectario. Las células epidérmicas del centro del «poro» poseen la pared externa convexa o en forma de pezón, lo que permite que la cutícula se incruste entre ellas.

En todas las especies que poseen «poro» la cutícula sigue un patrón constante: es muy gruesa sobre la epidermis secretora y se adelgaza gradualmente sobre el «poro». En los límites externos de la depresión central del NEF, la cutícula también posee fuertes cuñas que penetran profundamente entre las células. Así, la cutícula puede separarse de la epidermis secretora por la presión del néctar secretado, pero queda adherida en los bordes, evitando que el néctar escurra. También queda adherida al centro del "poro», donde al ser muy delgada ofrece el lugar más favorable para la salida del néctar.

Se encontraron diferencias en la forma del "poro" entre las distintas especies y entre las series de Turnera analizadas. En T. Aurelii, T. Kraporickasii y T. cuneiformis es crateriforme; en el resto de las especies del complejo T. ulmifolia es del tipo mesetiforme. En las otras especies de la serie Canaligerae la forma del "poro" es variable, destacándose $T$. stenophylla que posee un "poro» poco notable.

En la serie Leiocarpae los NEF presentan "poro" inconspicuo o no lo tienen; puede existir alguna zona de la epidermis más delgada o con cuñas cuticulares. La cuticula es de grosor uniforme y no supera las 6-8 $\mu \mathrm{m}$ de espesor, puede separarse o no de la epidermis secretora pero no se observó su ruptura. Berger (1919) no describe estos nectarios pero ilustra esquemáticamente a $T$. pinifolia con la cutícula adherida a la epidermis secretora.

Elias et al. (1975) no observaron el "poro» en T. ulmifolia. Según estos autores la excreción del néctar acumulado debajo de la cutícula se produce por ruptura de la misma. Esta también es la forma del excreción del néctar descripta en Passifora por Durkee (1982).

En todas las especies de Turnera estudiadas en este trabajo, la excreción del néctar sería transcuticular; en efecto, no se observó ruptura de la cutícula, lo cual sugiere que el «poro» es el lugar de la epidermis anatómicamente preparado para facilitar la excreción del néctar.

En la bibliografía se mencionan diversos mecanismos para la salida del néctar; según Fahn (1952 y 1979 a) la excreción puede realizarse por tricomas, por el parénquima a través de estomas o directamente por la epidermis, en éste caso la cutícula que la cubre puede romperse, ser permeable o poseer "poros» (microporos). Toth-Soma y Gulyás (1991) analizaron NEF de seis especies de Euphorbia con microscopio óptico y encontraron dos estructuras anatómicas para la excreción del néctar que deno- 
minaron "papilas secretoras» y "poros». Las primeras son grupos de células epidérmicas más altas y los últimos son zonas donde la epidermis secretora posee células más bajas. De acuerdo a las fotografías presentadas en ese trabajo, los "poros» serían estructuras semejantes a las disminuciones del espesor epidérmico encontradas en $T$. opifera.

Los caracteres anatómicos hallados en los NEF de la serie Canaligerae concuerdan básicamente con los descriptos por Berger (1919), quien los comparó con los NEF de Passiflora; Elias (1983) considera que son estructuras homólogas. De acuerdo al presente estudio, los NEF de la serie Leiocarpae son menos especializados, semejantes a los de Passiflora. Comparativamente, los NEF de la serie Canaligerae de Turnera son estructuras más elaboradas; la presencia de un "poro" con una cutícula diferencialmente engrosada representa una forma especializada de excreción del néctar. Su presencia en la mayoría de las especies de la serie Canaligerae coincide con la de otros caracteres que ubican a esta serie como una de las más evolucionadas del género (Arbo, 1986; González, 1993).

\section{Agradecimientos}

Deseo expresar mi agradecimiento a la Lic. María Mercedes Arbo, quien me facilitó el material fijado, por su valiosa dirección, revisión del texto y determinación del material. Al Lic. Orlando Popoff por la determinación de los hongos.

\section{Bibliografía}

ARBO, M.M. 1972. Estructura y ontogenia de los nectarios foliares del género Byttneria (Sterculiaceae). Darwiniana 17: 104-158.

-1986. Paraguay: centro importante de especiación en las Turneráceas. Candollea 41 (1): 211-218.

- 1987. Turneraceae. Flora del Paraguay. Conservatoire et Jardin Botaniques de Genève. Missouri Botanical Garden.

- 1993. Nuevas especies americanas de Turnera (Tumeraceae). Bonplandia 7 (1-4): 57-93.

BAHADUR, B.; N. RAMA SWAMY; A. CHATURVEDI \& S.M. FAROOQUI. 1985. Floral nectaries in two species of Turnera L. (Turneraceae). New Botanist $12(2-4)$ : 117 127.

BENTLEX, B. 1977. Extrafloral nectaries and protection by pugnacious bodyguard. Ann. Rev. Ecol. Syst. 8: 407-
427.

—. \& T. ELIAS Eds. 1983. The biology of nectaries. Columbia University Press. 259 págs.

BERGER, M. G. 1919. Etude organographique, anatomique et pharmacologique de la famille des Turnéracées. Thèse pour le Doctorat de L'Université, Lille.

CASPARY, R. 1848. De Nectariis. Elberfeld. Dato tomado de Bentley \& Elias, 1983.

DELPINO, F. 1875. Rapporti tra insetti e tra nettarii estranuziali in alcune piante. Boll. Ital. Soc. Entomol. 7: 69-90. Dato tomado de Bentley \& Elias, 1983.

DIZEO de STRITTMATTER, C.G. 1973. Nueva técnica de diafanización. Bol. Soc. Argent. Bot. 15 (1): 126-129.

DURKEE, L.T. 1982. The floral and extrafloral nectaries of Passiflora. II. The extrafloral nectaries. Amer. J. Bot. 69: 1420-1428.

- D.J. GAAL \& W.H. REISNER. 1981. The floral and extrafloral nectaries of Passiflora. I. The floral nectaries. Amer. J. Bot. 68: 453-462.

ELIAS, T.S. 1983. Extrafloral Nectaries: their structure and distribution :174-203. En Bentley \& Elias, 1983.

-W.R. ROZICH \& L. NEWCOMBE. 1975. The foliar and floral nectaries of Turnera ulmifolia. Amer. J. Bot. 62 (6): 570-576.

-.., \& H. GELBAND. 1976. Morphology and anatomy of floral and extrafloral nectaries of Campsis (Bignoniaceae). Amer. J. Bol. 63 (10): 1349-1353.

FAHN, A. 1952. On the structure of the floral nectaries. Botanical Gazette 113: 464-470.

-1953. The topography of the nectaries in the flower and its phylogenetic trend. Phytomorphology 3: 424-426.

1979 a. Secretory tissues in plants. Academic Press. 302 págs.

_ $1979 \mathrm{~b}$. Ultrastructure of nectaries in relation to nectar secretion. Amer. J. Bot. 66 (8): 977-985.

-1988. Secretory tissues in vascular plants. Tansley Revicw 14. New Phytol. 108: 229-257.

FOSTER, A.S. 1934. The use of tannic acid and iron chloride for staining cells walls in meristematic tissue. Stain. Technol. 9: 91-92.

-1956. Plant Idioblasts: remarkable examples of cell specialization. Protoplasma 46: 184-193.

FREY-WYSSLING, A. 1955. The phloem supply to the nectaries. Acta Bot. Neerl. 4 (3): 358-369.

GABE, M. 1968. Téchniques histologiques. Mason et Cie. Editeurs.

GONZALEZ, A.M. 1993. Anatomía y vascularización floral de Piriqueta racemosa, Tumera Hassleriana y Turnera Joelii (Turneraceae). Bonplandia 7 (1-4): 143184.

JOHANSEN, D.A. 1940. Plant microtechnique. McGrawHill Book Co. New York. 511 págs.

JOHNSON, M.A. 1958. The epiphyllous flowers of Turnera and Helwingia. Bull. Torrey Bot. Club 85 (5): 313-323.

KEELER, K.\& R. KAUL. 1979. Morphology and distribution of petiolar nectaries in Ipomoea (Convolvulaceae). Amer. J. Bot. 66 (8): 946-952.

KOPTUR, S. 1992. Extrafloral nectary-mediated interactions between insects and plants. En Bernays, E. Insectsplants interactions. CRC Press. Vol. 4: 81-129.

LANZA, J. 1988. Ant preferences for Passiflora nectar 
mimics that contain amino acids. Biotropica 20 (4) 341-344.

LERSTEN, N.R. \& K.A. CARVEY. 1974. Leaf anatomy of Ocotillo (Fouquieriasplendens, Fouquieriaceae) especially vein endings and associated veinlet elements. Canad. J. Bot. 52: 2017-2021

MC KEY, D. 1988. Promising new directions in the study of ant-plant mutualisms. Proceedings of the XIV International Botanical Congress. Köeltz Scientific Books :335-355.

MC LAIN, D.K. 1983. Ants, extrafloral nectaries and herbivory on the Passion Vine, Passiflora incarnata. Amer. Midl. Naturalist. 110 (2): 433-439.

METCALFE, C. \& L. CHALK. 1979. Anatomy of the Dycotiledons. Vol. I. Clarendon Press. Oxford. 276 págs.

MORELLATO, L. \& P. OLIVEIRA. 1994. Extrafloral nectaries in the tropical tree Guarea macrophylla (Meliaceae). Canad. J. Bot. 72: 157-160.

O'DOWD, D.J. \& E.A. CATCHPOLE. 1983. Ants and extrafloral nectaries: no evidence for plant protection in Helichrysum spp - ant interactions. Oecologia 59: 191-200.

OKOLI, B. \& F.A. ONOFEGHARA. 1984. Distribution and morphology of extrafloral nectaries in some Cucurbitaceae. Bot. J. Linn. Soc. 89: 153-164.

RACHMILEVITZ, T. \& A. FAHN. 1975. The floral nectary of Tropaeolum majus L. The nature of the secretory cells and the manner of the nectar secretion. Ann. Bot. 39: $721-728$.

RAO, T.A. 1991. Compendium of foliar sclereids in angiosperms: morphology and taxonomy. Wiley Eastern Limited Eds. 278 págs.

— \&S. DAS. 1979. Comparative typology and taxonomic value of foliar sclereids in Capparis Linn. Phyta 2-3:7386.

— \& S. CHAKRABORTI. 1982. On the vein termini idioblasts in Reaumuria Hasselq. ex L. (Tamaricaceae). Curr. Sci. 51 (18): 907-908.

SCHEMSKE, D. 1982. Ecological correlates of neotropical mutualism: ants assemblages at Costus extrafloral nectaries. Ecology 63 (4): 932-941.

SCHMID, R. 2988. Reproductive versus extra-reproductive nectaries. Historical perspective and terminological recomendations. Bot. Rev. 54 (2): 179-232.

TOTH-SOMA, L.T. \& S. GULYAS. 1991. Anatomical connection between intracellular and extracellular secretions in Euphorbia genus. Acta Biol. (Szeged). 37: 19-23.

TUCKER, S.C. 1964. The terminal idioblasts in magnoliaceous leaves. Amer. J. Bot. 51: 1051-1052.

ZIMMERMANN, J.G. 1932. Über die extrafloralen Vektarien der Angiospermen. Beih. Bot. Centralbl. 49: 99-196. Dato tomado de Bentley \& Elias, 1983. 